\title{
A Novel Ansamycin, Naphthomycin K from Streptomyces sp.
}

\author{
Chunhua Lu, Yuemao Shen
}

Received: July 7, 2007 / Accepted: September 20, 2007

(C) Japan Antibiotics Research Association

\begin{abstract}
One novel ansamycin, namely naphthomycin $\mathrm{K}$, together with two known naphthomycins A and E, were isolated from the commensal strain Streptomyces sp. CS of the medicinal plant Maytenus hookeri. Their structures were elucidated by the analysis of NMR and MS data. Naphthomycin K showed evident cytotoxicity against P388 and A-549 cell lines, but no inhibitory activities against Staphylococcus aureus and Mycobacterium tuberculosis.
\end{abstract}

Keywords ansamycin, naphthomycin K, Streptomyces sp. CS

In our continuous search for maytansine-producing commensal microorganisms from the medicinal plant Maytenus hookeri, we found that the culture extract of Streptomyces sp. CS [1], one of the commensal microorganisms isolated from the tissue cultures of M. hookeri, showed potent antifungal activity against Penicillium avellaneum UC-4376 by the diffusion assay on agar plates and produced an array of chloride-containing compounds as indicated by LC-ESI-MS detection (data not shown). Naphthomycins A and E $(\mathbf{1}, \mathbf{2})$ were isolated from the fermentation extracts of the strain CS cultivated on ISP2 agar medium (data not shown), and antifungal activity-guided fractionation afforded a new macrolide antibiotic, named 24-demethyl-bafilomycin $\mathrm{C}_{1}$, obtained from the extracts of large scale submerged fermentations in ISP2 liquid medium [1]. The presence of chlorine-

Y. Shen (Corresponding author), C. Lu: Key Laboratory of the Ministry of Education for Cell Biology and Tumor Cell Engineering; Xiamen Engineering Research Center of Marine Microbial Drug Discovery; Fujian Laboratory of Pharmaceutical Engineering; School of Life Science, Xiamen University, Xiamen, Fujian 361005, P. R. China, E-mail: yshen@xmu.edu.cn containing compounds such as $\mathbf{1}$ in this strain drew our attention because maytansinoids contain chlorine, and both belong to the type I polyketide family. Guided by analysis of extracts from fermentations in nine different culture media for antifungal activity and LC-ESI-MS profile, ISP3 was selected and used for large-scale solid state fermentation. A novel ansamycin, naphthomycin K (3, Fig. 1) as well as $\mathbf{1}$ and $\mathbf{2}$ were isolated from the extract of 14 liters of agar plate fermentation of strain CS.

1 was determined to have the molecular formula $\mathrm{C}_{40} \mathrm{H}_{46}{ }^{35} \mathrm{ClNO}_{9}(\mathrm{~m} / \mathrm{z}$ 719.2866, calcd.: 719.2861), and $\mathrm{C}_{40} \mathrm{H}_{46}{ }^{37} \mathrm{ClNO}_{9}(\mathrm{~m} / \mathrm{z}$ 721.2812, calcd: 721.2832), which indicated the presence of chlorine in this molecule. The ${ }^{13} \mathrm{C}$-NMR and DEPT spectra showed forty carbon signals

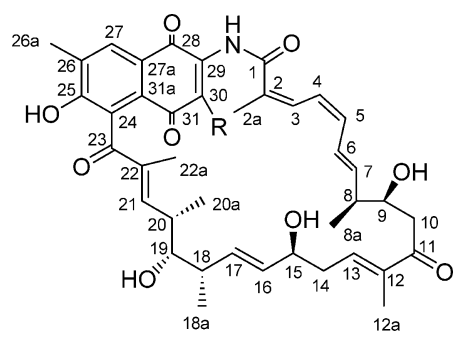

$\mathrm{R}=\mathrm{Cl}$ Naphthomycin A (1)

$\mathrm{R}=\mathrm{H}$ Naphthomycin $\mathrm{E}(2)$

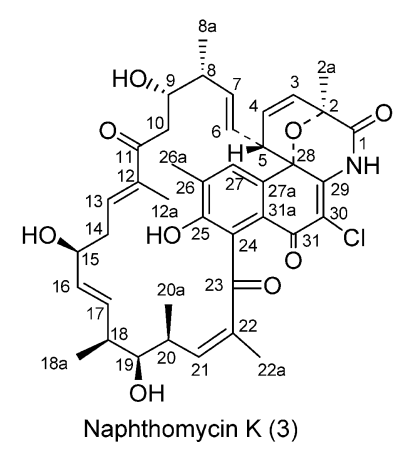

Fig. 1 Structures of naphthomycins A, E and $K$ isolated from Streptomyces sp. CS. 
Table 1 The NMR data for naphthomycin A $(\mathbf{1})^{a}$

\begin{tabular}{|c|c|c|c|c|}
\hline No & $\delta^{13} \mathrm{C}$ & $\delta^{1} H^{\mathrm{b}}$ & $\mathrm{HMBC}$ & ${ }^{1} \mathrm{H}-{ }^{1} \mathrm{H}$ COSY \\
\hline 1 & 168.8 & - & - & - \\
\hline 2 & 131.5 & - & - & - \\
\hline 3 & 128.7 & $6.57(\mathrm{dd}, 1.5,9.9)$ & $C-5, C-2, C-2 a$ & $\mathrm{H}-4$ \\
\hline 4 & 123.0 & $6.04(d, 10.0)$ & $C-7, C-5, C-3, C-6$ & $\mathrm{H}-3, \mathrm{H}-5$ \\
\hline 5 & 132.0 & $6.04(d, 10.0)$ & $C-7, C-3, C-6$ & $\mathrm{H}-4, \mathrm{H}-6$ \\
\hline 6 & 126.9 & $6.47(\mathrm{dd}, 10.0,15.0)$ & C-8 & $\mathrm{H}-5, \mathrm{H}-7$ \\
\hline 7 & 139.9 & $5.42(d d, 10.0,15.0)$ & C-5, C-9, C-8, C-8a & $\mathrm{H}-6, \mathrm{H}-8$ \\
\hline 8 & 44.9 & $2.24(\mathrm{~m})$ & C-9 & $\mathrm{H}-7 \mathrm{H}-9, \mathrm{H}-8 \mathrm{a}$ \\
\hline 9 & 72.8 & $3.51(\mathrm{~m})$ & C-7, C-8, C-8a & $\mathrm{H}-10, \mathrm{H}-8$ \\
\hline \multirow[t]{2}{*}{10} & 40.5 & $2.46(\mathrm{dd}, 7.3,17.1)$ & $C-9, C-8$ & $\mathrm{H}-9, \mathrm{H}-10$ \\
\hline & & $3.24(\mathrm{dd}, 2.8,17.1)$ & C-9, C-8 & $\mathrm{H}-10$ \\
\hline 11 & 203.7 & - & - & - \\
\hline 12 & $137.6^{c}$ & - & - & - \\
\hline 13 & 142.9 & $6.72(t, 5.7)$ & C-11, C-15, C-14, C-12a & $\mathrm{H}-14$ \\
\hline 14 & 36.1 & $2.26(\mathrm{~m})$ & C-13, C-12, C-15 & $\mathrm{H}-13, \mathrm{H}-15$ \\
\hline 15 & 72.2 & $3.94(\mathrm{~m})$ & C-13, C-17, C-14 & $\mathrm{H}-16, \mathrm{H}-14$ \\
\hline 16 & 136.5 & $5.61(\mathrm{dd}, 8.0,15.0)$ & C-15, C-18, C-14, C-18a & $\mathrm{H}-17, \mathrm{H}-15$ \\
\hline 17 & 134.0 & $5.37(d d, 9.7,15.1)$ & C-15, C-18, C-18a & $\mathrm{H}-16, \mathrm{H}-18$ \\
\hline 18 & 41.3 & $2.15(\mathrm{~m})$ & C-19 & $\mathrm{H}-17, \mathrm{H}-19, \mathrm{H}-18 \mathrm{a}$ \\
\hline 19 & 76.9 & $3.04(d d, 2.2,9.8)$ & C-21, C-17, C-18a, C-20a & $\mathrm{H}-18$ \\
\hline 20 & 33.6 & $2.65(\mathrm{~m})$ & C-21, C-20a & $\mathrm{H}-21, \mathrm{H}-20 \mathrm{a}$ \\
\hline 21 & 147.1 & $5.89(\mathrm{dd}, 1.3,10.2)$ & C-23, C-22a & $\mathrm{H}-20$ \\
\hline 22 & $137.8^{c}$ & - & - & - \\
\hline 23 & 201.8 & - & - & - \\
\hline 24 & 119.9 & - & - & - \\
\hline 25 & 161.4 & - & - & - \\
\hline 26 & 133.6 & - & - & - \\
\hline 27 & 131.4 & 7.90 (s) & C-25, C-29, C-26a & - \\
\hline $27 a$ & 121.7 & - & - & - \\
\hline 28 & 178.9 & - & - & - \\
\hline 29 & $134.3^{d}$ & - & - & - \\
\hline 30 & $136.3^{d}$ & - & - & - \\
\hline 31 & 178.1 & - & - & - \\
\hline $31 a$ & 134.3 & - & - & - \\
\hline $2 a$ & 20.5 & $2.07(\mathrm{~d}, 1.2,3 \mathrm{H})$ & $\mathrm{C}-1, \mathrm{C}-2, \mathrm{C}-3, \mathrm{C}-4$ & - \\
\hline $8 a$ & 17.2 & $1.13(\mathrm{~d}, 6.5,3 \mathrm{H})$ & $C-7, C-9, C-8$ & $\mathrm{H}-8$ \\
\hline $12 a$ & 11.0 & $1.65(\mathrm{~s}, 3 \mathrm{H})$ & C- $11, \mathrm{C}-13, \mathrm{C}-12$ & - \\
\hline $18 a$ & 16.1 & $0.89(\mathrm{~d}, 6.7,3 \mathrm{H})$ & C-17, C-19, C-18 & $\mathrm{H}-18$ \\
\hline $20 a$ & 10.5 & $0.78(\mathrm{~d}, 6.7,3 \mathrm{H})$ & C-21, C-19, C-20 & $\mathrm{H}-20$ \\
\hline $22 a$ & 12.5 & $1.97(\mathrm{~d}, 1.1,3 \mathrm{H})$ & C-23, C-21, C-22 & - \\
\hline $26 a$ & 16.4 & $2.33(\mathrm{~s}, 3 \mathrm{H})$ & C-25, C-26, C-27 & - \\
\hline $\mathrm{NH}$ & - & $8.40, \mathrm{~s}$ & C-1, C-29 & - \\
\hline
\end{tabular}

${ }^{a}{ }^{1} \mathrm{H}$ - and ${ }^{13} \mathrm{C}-\mathrm{NMR}$ spectra were obtained at 400 and $100 \mathrm{MHz}$ on Bruker AM-400 with TMS as internal standard, 2D NMR spectra were obtained at $500 \mathrm{MHz}$ on Bruker DRX-500, respectively, and measured in $\mathrm{CDCl}_{3}$ at room temperature.

${ }^{b}$ Coupling constants are presented in $\mathrm{Hz}$. Unless otherwise indicated, all proton signals integrate to $1 \mathrm{H}$.

$c, d$ The assignments are interchangeable. 
Table 2 The NMR assignments for naphthomycin K $(\mathbf{3})^{a}$

\begin{tabular}{|c|c|c|c|c|}
\hline No & ${ }^{13} \mathrm{C}$ & ${ }^{1} \mathrm{H}^{\mathrm{b}}$ & $\mathrm{HMBC}$ & ${ }^{1} \mathrm{H}-{ }^{1} \mathrm{H}$ COSY \\
\hline 1 & 168.6 & - & - & - \\
\hline 2 & 76.3 & - & - & - \\
\hline 3 & 127.1 & $5.91(d, 10.3)$ & $C-2, C-5$ & $\mathrm{H}-4$ \\
\hline 4 & 130.2 & $5.99(\mathrm{dd}, 4.7,10.2)$ & $\mathrm{C}-2$ & $\mathrm{H}-3, \mathrm{H}-5$ \\
\hline 5 & 52.5 & $2.84(\mathrm{dd}, 4.5,9.0)$ & $C-4, C-6$ & $\mathrm{H}-4$ \\
\hline 6 & 130.0 & $5.03(d d, 8.9,15.5)$ & C-6, C-5, C-8 & $\mathrm{H}-7, \mathrm{H}-5$ \\
\hline 7 & 133.8 & $5.35(d d, 7.7,16.6)$ & C-5, C-8, C-8a & $\mathrm{H}-6$ \\
\hline 8 & 41.7 & $2.32(\mathrm{~m})$ & C-6 & $\mathrm{H}-7, \mathrm{H}-8 \mathrm{a}$ \\
\hline 9 & 71.2 & $3.86(\mathrm{brd}, 9.8)$ & - & $\mathrm{H}-8$ \\
\hline 10 & 38.5 & $\begin{array}{l}2.44(\mathrm{~m}) \\
2.65(\mathrm{brd}, 17.8)\end{array}$ & C-11 & $\mathrm{H}-10$ \\
\hline 11 & 202.3 & - & - & - \\
\hline 12 & 140.5 & - & - & - \\
\hline 13 & 137.8 & 6.55 (br s) & $\mathrm{C}-11, \mathrm{C}-12 \mathrm{a}$ & $\mathrm{H}-14$ \\
\hline 14 & 35.3 & $2.77(\mathrm{~m}), 2.44(\mathrm{~m})$ & C-11, C-15 & $\mathrm{H}-14$ \\
\hline 15 & 68.8 & 4.56 (br s) & $\mathrm{C}-13$ & $\mathrm{H}-14$ \\
\hline 16 & 133.9 & $5.59(\mathrm{brd}, 7.9)$ & C-15, C-18 & - \\
\hline 17 & 133.2 & 5.59 (br s) & C-15, C-18 & $\mathrm{H}-18$ \\
\hline 18 & 41.9 & $2.32(\mathrm{~m})$ & - & $\mathrm{H}-17, \mathrm{H}-18 \mathrm{a}$ \\
\hline 19 & 75.5 & $3.15(d, 9.5)$ & C-20a & $\mathrm{H}-18$ \\
\hline 20 & 34.3 & $2.77(\mathrm{~m})$ & $\mathrm{C}-20 \mathrm{a}, \mathrm{C}-21, \mathrm{C}-22$ & $\mathrm{H}-21, \mathrm{H}-20 \mathrm{a}$ \\
\hline 21 & 142.0 & $6.12(d, 8.6)$ & $\mathrm{C}-23, \mathrm{C}-22 \mathrm{a}$ & $\mathrm{H}-20$ \\
\hline 22 & 139.8 & - & - & - \\
\hline 23 & 201.5 & - & - & - \\
\hline 24 & 123.1 & - & - & - \\
\hline 25 & 154.6 & - & - & - \\
\hline 26 & 130.9 & - & - & - \\
\hline 27 & 130.0 & 7.30 (s) & C-25, C-31a, C-28 & - \\
\hline $27 a$ & 136.0 & - & - & - \\
\hline 28 & 75.4 & - & - & - \\
\hline 29 & 107.6 & - & - & - \\
\hline 30 & 122.1 & - & - & - \\
\hline 31 & 176.2 & - & - & - \\
\hline $31 a$ & 127.5 & - & - & - \\
\hline $2 a$ & 20.4 & $1.68(\mathrm{~s}, 3 \mathrm{H})$ & $C-1, C-3, C-2$ & - \\
\hline $8 a$ & 14.2 & $0.57(\mathrm{~d}, 7.2,3 \mathrm{H})$ & C-7, C-9, C-8 & $\mathrm{H}-8$ \\
\hline $12 a$ & 11.5 & $1.74(\mathrm{~s}, 3 \mathrm{H})$ & $\mathrm{C}-11, \mathrm{C}-12 \mathrm{a}, \mathrm{C}-13$ & - \\
\hline $18 a$ & 17.3 & $0.99(\mathrm{~d}, 6.7,3 \mathrm{H})$ & C-17, C-19, C-18 & $\mathrm{H}-18$ \\
\hline $20 a$ & 10.8 & $0.83(\mathrm{~d}, 6.6,3 \mathrm{H})$ & C-21, C-19, C-20 & $\mathrm{H}-20$ \\
\hline $22 a$ & 12.4 & $2.07(\mathrm{~d}, 1.1,3 \mathrm{H})$ & C-23, C-21, C-22 & $\mathrm{H}-22$ \\
\hline $26 a$ & 16.6 & $2.30(\mathrm{~s}, 3 \mathrm{H})$ & C-25, C-26 & - \\
\hline $\mathrm{NH}$ & - & $7.81, \mathrm{~s}$ & C-28, C-2, C-1 & - \\
\hline
\end{tabular}

${ }^{a}{ }^{1} \mathrm{H}$ - and ${ }^{13} \mathrm{C}-\mathrm{NMR}$ spectra were obtained at 400 and $100 \mathrm{MHz}$ on Bruker AM-400 with TMS as internal standard, 2D NMR spectra were obtained at $500 \mathrm{MHz}$ on Bruker DRX-500, respectively, and measured in $\mathrm{CDCl}_{3}$ at room temperature.

${ }^{b}$ Coupling constants are presented in $\mathrm{Hz}$. Unless otherwise indicated, all proton signals integrate to $1 \mathrm{H}$. 
for seven methyl, two methylene, sixteen methine, and fifteen quaternary carbon atoms, respectively. Inspection of the NMR data (proton, carbon, DEPT, HMQC and HMBC) and ${ }^{1} \mathrm{H}-{ }^{1} \mathrm{H}$ COSY spectra (Table 1) assigned the planar structure of 1 to be naphthomycin A [2 6]. The complete NMR assignments were unambiguously carried out on the basis of HMQC and HMBC experiments (Table 1).

2 was determined to have the molecular formula $\mathrm{C}_{40} \mathrm{H}_{47} \mathrm{NO}_{9}$ by HREI-MS ( $m / z$ 685.3294, calcd.: 685.3299) and was determined to be naphthomycin $\mathrm{E}$ by comparison of its ${ }^{1} \mathrm{H}$ - and ${ }^{13} \mathrm{C}-\mathrm{NMR}$ spectral data with those of $\mathbf{1}$ and reference 7 .

3, $[\alpha]_{\mathrm{D}}^{24}+112(c \quad 0.25, \mathrm{MeOH})$, was isolated as a colorless powder. ESI-MS gave molecular ions at $\mathrm{m} / \mathrm{z} 742.2$ and $744.2[\mathrm{M}+\mathrm{Na}]^{+}$in the natural abundance isotope ratio of ${ }^{35} \mathrm{Cl}$ and ${ }^{37} \mathrm{Cl}$, indicating the presence of chloride in the structure. The ${ }^{13} \mathrm{C}$-NMR and DEPT spectra showed forty carbon signals for seven methyl, two methylene, sixteen methine, and fifteen quaternary carbon atoms. The HMQC, $\mathrm{HMBC}$ and ${ }^{1} \mathrm{H}-{ }^{1} \mathrm{H}$ COSY experiments revealed a naphthomycin-type structure and determined the NMR assignments for 3. The carbons at $\delta 76.3$ (C-2), 75.4/75.5 (C-28) and $\delta 52.5$ (C-5) (Table 2) showed distinct differences compared to those of $\mathbf{1}$, whereas all other signals are almost the same in both spectra with minor differences of chemical shift. The ketone atoms at $\delta 178.9$ (C-28), the olefinic carbons at $\delta 131.5$ (C-2) and 132.0 (C$5)$ in 1 was replaced by oxygenated carbon at $\delta 75.4 / 75.5$ (C-28), 76.3 (C-2) and a quaternary carbon at $\delta 52.5$ (C-5) in 3, respectively. The chemical shifts of these three carbons suggested a direct connection between carbons C-5 and $\mathrm{C}-28$, and a connection between $\mathrm{C}-2$ and $\mathrm{C}-28$ via an oxygen atom. This was further supported by the molecular formula $\mathrm{C}_{40} \mathrm{H}_{46} \mathrm{ClNO}_{9} \mathrm{Na}$ derived by HRESI-MS $(\mathrm{m} / \mathrm{z}$ 742.2774, calcd.: 742.2758) and an NOE effect between $\delta_{\mathrm{H}}$ 5.03 (H-6) and 2.30 (H-26a). ESI-MS gave the molecular ion of the fully acetylated $\mathbf{3}$ as $\mathrm{m} / \mathrm{z} 910[\mathrm{M}+\mathrm{Na}]^{+}$, which suggested the presence of four free hydroxyl groups in the structure, and further confirmed the connection between C2 and C-28 via an oxygen. Therefore, $\mathbf{3}$ was determined to be a new ansamycin named naphthomycin K (Fig. 1). The stereochemistry of 3 at C-8, C-9, C-15, C-18, C-19 and C20 is suggested to be the same as $\mathbf{1}$ based on NMR data comparison. The relative configurations of $\mathrm{C}-2, \mathrm{C}-5$ and C-28 were resolved by analyzing the results of ROESY experiments, which showed NOE effects between the protons at $\delta_{\mathrm{H}} 1.68(\mathrm{H}-2 \mathrm{a})$ and $5.91(\mathrm{H}-3)$, and $2.30(\mathrm{H}-26 \mathrm{a})$ and $7.30(\mathrm{H}-27), 0.57(\mathrm{H}-8 \mathrm{a})$, and $2.84(\mathrm{H}-5)$ and $5.99(\mathrm{H}-$ 4), 5.35 (H-7), 5.03 (H-6), and $7.30(\mathrm{H}-27)$ and $5.03(\mathrm{H}-6)$ (Fig. 1).

Ansamycin antibiotics of the naphthalenic subgroup are characterised by the presence of a bicyclic aromatic or quinonoid nucleus across which a polyketide chain is linked to form a macrocyclic lactam [8], as exemplified by $1[2,3]$, naphthomycins B and C [9]. Members of this subgroup display a range of potent antibacterial and antifungal activities [5]. In our experiments, using disk diffusion testing [10], $\mathbf{1}$ isolated as the main component showed evident inhibitory activity against $P$. avellaneum UC-4376, Staphylococcus aureus and Mycobacterium tuberculosis (obtained from Key Laboratory for Conservation and Utilization of Bioresources, Yunnnan University) in dose-dependent manner, respectively (data not shown). But $\mathbf{3}$ showed no inhibitory zones against the tested microorganisms at $200 \mu \mathrm{g} /$ disc.

Previous studies showed that naphthomycin has antineoplastic activity and further investigated its mode of action [11]. In our experiments, 1 showed cytotoxic activity against P388 and A-549 cells by sulforhodamine B and microculture tetrozolium methods at $\mathrm{IC}_{50} 0.07$ and $3.17 \mu \mathrm{M}$ measured at 48 hours after exposure, respectively.

Acknowledgements This work was partially supported by the National Science Fund for Distinguished Young Scholars to Y.-M. Shen (30325044) and the National Natural Science Foundation of China (30430020).

\section{References}

1. Lu C, Shen Y. A new macrolide antibiotic with antitumor activity produced by Streptomyces sp. CS, a commensal microbe of Maytenus hookeri. J Antibiot 56: 415-418 (2003)

2. Balerna M, Keller-Schierlein W, Martius C, Wolf H, Zähner H. Naphthomycin, an antimetabolite of vitamin $\mathrm{K}_{1}$. Arch Mikrobiol 65: 303-317 (1969)

3. Williams TH. Naphthomycin, a novel ansa macrocyclic metabolite. Proton NMR spectra and structural elucidation using lanthanide shift reagent. J Antibiot 28: 85-86 (1975)

4. Lee JP, Tsao SW, Chang CJ, He XG, Floss HG. Biosynthesis of naphthomycin A in Streptomyces collinus. Can J Chem 72: 182-187 (1994)

5. Mukhopadhyay T, Franco CMM, Reddy GCS, GanguliA BN, Fehlhaber HW. A new ansamycin antibiotic, naphthomycin H from Streptomyces species Y-83, 40369. J Antibiot 38: 948-951 (1985)

6. Keller-Schierlein W, Meyer M, Zeeck A, Damberg M, Machinek R, Zahner H, Lazar G. Isolation and structural Elucidation of naphthomycins $\mathrm{b}$ and C. J Antibiot 36: 484-492 (1985)

7. Michael M, Walter Ks, Salva M, Hans Z, Annalaura S. Metabolites of microorganisms. 236. Sulfur-containing ansa compounds of the naphthomycin type. Helvetica Chimica 
Acta 69: 1356-1364 (1986)

8. Hooper AM, Rickards RW. 3-Amino-5-hydroxybenzoic acid in antibiotic biosynthesis. XI. Biological origins and semisynthesis of thionaphthomycins, and the structure of naphthomycin I and J. J Antibiot 51: 845-851 (1998)

9. Keller-Schierlein W, Meyer M, Zeeck A, Damberg M, Machinek M, Zähner R, Lazar H. Isolation and structure elucidation of naphthomycins B and C. J Antibiot 36: 484-492 (1984)
10. Jorgensen JH, Turnidge JD, Washington JA. Antibacterial Susceptibility Tests: Dilution and Disk Diffusion Methods. In: Manual of Clinical Microbiology, 7th edn. (Murray PR ed.). pp. 1526-1543, American Society for Microbiology, Washington DC (1999)

11. Okabe T, Yuan BD, Isone F, Sato I, Fukazawa H, Nishimura T, Tanaka N. Studies on antineoplastic activity of naphthomycin, a naphthalenic ansamycin, and its mode of action. J Antibiot 38: 230-235 (1985) 